\title{
Comparação de padrão hematológico de vacas de leite no início e final de gestação
}

Claudijane de Carvalho Matos", Luís Paulo Nemézio Bezerra Pinheiro, Euclides Figueredo Leite, José Hugo dos Santos, Kelly Cunha Vital, Taynara Farias Teixeira de Santana, David José de Castro Martins, Karina Oliveira Pessoa, Hélio Martins de Aquino Neto, Marcia Kikuyo Notomi

Medicina Veterinária, Universidade Federal de Alagoas (UFAL), Maceió, AL, Brasil

*Autor correspondente

e-mail: claudijanematos@gmail.com

\section{Resumo}

A cadeia produtiva do leite desempenha um papel relevante no suprimento de alimentos e na geração de emprego e renda para a população. Compreender os padrões sanguíneos, bem como as variações nesses parâmetros conforme o período produtivo e categoria do animal são de fundamental importância para o desenvolvimento da eficiência dessa agroindústria. Objetivou-se nesse trabalho avaliar e comparar o perfil hematológico de vacas leiteiras em períodos distintos da gestação. Foram estudadas 30 vacas prenhes, hígidas, provenientes de cooperativas leiteiras do estado de Alagoas, submetidas ao mesmo manejo. Sendo divididas em: Grupo T1 - 15 vacas com aproximadamente 12 semanas de gestação, e Grupo T2 15 vacas com aproximadamente 32 semanas de gestação. As coletas de sangue ocorreram após a ordenha da manhã, por punção da veia jugular, acondicionando o material em tubos com EDTA. No laboratório foi realizada a contagem de hemácias, mensuração da hemoglobina, leucócitos totais e plaquetas por meio de analisador hematológico Mindray BC-2800vet. O volume corpuscular médio (VCM) e a concentração da hemoglobina corpuscular média (CHCM) foram calculados utilizando-se fórmula padrão. 0 volume globular (VG) foi avaliado pela técnica do microhematócrito e a concentração da proteína total plasmática (PPT) por refratômetria; a contagem diferencial leucocitária, em esfregaço sanguíneo corado. Foi realizada uma análise estatística descritiva dos parâmetros hematológicos dos grupos. A análise de variância entre T1 e T2 foi realizada utilizando-se o teste de Mann Whitney. Tanto no grupo T1 quanto no T2, os valores médios dos parâmetros avaliados estavam dentro dos valores de referência da espécie bovina e apresentaram uma distribuição normal na análise estatística. Na comparação entre os parâmetros do eritrograma foi possível verificar uma redução significativa no número médio de hemácias no Grupo T2, entretanto essa alteração não foi observada na concentração de hemoglobina e volume globular. Mas, ao avaliar VCM e CHCM, a diferença estatística também foi constatada para os dois parâmetros, indicando que apesar da 
redução no número de hemácias, induzida por uma redistribuição dos componentes sanguíneos, a medula óssea mantém o volume corpuscular pela liberação de precursores eritrocitários. No leucograma, não foi observada diferença estatística no número de leucócitos totais, neutrófilos, linfócitos e eosinófilos. Não foi realizada comparação entre a contagem de basófilos e monócitos por causa da pequena amostragem. Não foi observada diferença estatística na contagem de plaquetas entre os dois grupos, porém foi observada uma significativa redução $(\mathrm{P}<0,05)$ na concentração de proteínas plasmática total no Grupo T2 que, entre outros motivos, pode se dar pela redução da ingestão de alimentos esperada para a fase final gestacional. Portanto, conclui-se que apesar da redução do número de hemácias observada no final de gestação, a concentração de hemoglobina e volume globular não sofrem alterações significativas. 